\title{
Innovative Research on Basic Education System of Visual Communication Design
}

\author{
$\mathrm{Ke} \mathrm{Li}$ \\ School of Art \\ Yangtze University \\ Jingzhou, Hubei, China 434020
}

\begin{abstract}
The visual communication design specialty in many colleges and universities is looking for a direction suitable for their own development according to the education situation of China's visual communication design specialty. Therefore, we must learn from the excellent education concept and systematic basic system of visual communication design specialty in the world, so as to have an in-depth understanding of the internal concept of Bauhaus design education as the core. And the basic education system suitable for China's visual communication design specialty shall be further explored according to the history and reality of China.
\end{abstract}

Keywords—visual communication design; basic education; innovation

\section{INTRODUCTION}

With the development of China's modernization, the visual communication design specialty also ushers in a new stage of development. Now China's visual communication design education has separated from the original artistic design, having strong cross relationship with media design, animation design, etc. The basic education of visual communication design is the visual creation behavior with plane, solid and color as the main elements. And the research on its basic education system is the teaching research on such visual elements as plan, solid and color.

\section{CURRENT BASIC SYSTEM OF VISUAL COMMUNICATION DESIGN EDUCATION}

Visual communication design specialty is generated and developed with China's reform and opening up, having a short history in China. At present, most of the basic system of China's visual communication design is still continuing the system that established when this specialty is first set up. Three decades have passed, and there are no large changes, which is not good for development of China's modern design. Because visual communication design is generated quite late in China, and there was no complete and systematic system at that time, so the early art design specialty was influenced more by the art of painting, and the basic courses were mainly built by copying the sketch and color of painting. The realistic training requirements in painting haven't been changed. During this period, the German Bauhaus design system was introduced into China, and there may be avoidable mislead because of the incomplete understanding of the system and simple introduction of the teaching materials translation from neighboring countries and regions, and just apply them to the design education in China. At that time, the most meaningful shall be the introduction of plane, color, and solid, but these three components have always presented many shortages, many principles repeat from others, and the connection between three components and other professional courses has not been perfected.

From the perspective of traditional Chinese arts and crafts education, among the introduction of western education system of visual communication design, the traditional arts and crafts courses are reduced significantly, and China's arts and crafts basic system walks into the state of disorder, which indirectly lead to the young designers' sense of loss and disagree toward China's traditional craft and culture. The disadvantage of such basic system of visual communication design is quite obvious. How to develop China's visual communication design teaching? How to construct a complete set of rigorous basic education system of visual communication design? This is an issue worthy to be thought by us education workers of visual communication design specialty.

\section{INNOVATION ORIENTATION OF THE BASIC EDUCATION SYSTEM OF VISUAL COMMUNICATION DESIGN}

According to the situation of China's visual communication design specialty education, the design specialty of many colleges and universities is looking for a suitable development direction of their own. Therefore, we must learn from the excellent education concept and systematic basic system in the world, so as to have an in-depth understanding of the internal concept of Bauhaus design education as the core. And the basic education system suitable for China's visual communication design shall be further explored according to the history and reality of China.

\section{A. Basic System from Painting Education to Design Education}

From the perspective of current basic system, as for the visual communication design specialty in many colleges and universities, students' realistic training is still conducted through the basic courses such as sketch and color. But from the perspective of the characteristics of visual communication design specialty, such realistic is not that necessary. And under the current exam-oriented education system, students generally 
have the preliminary realistic training ability before they entered into the school. The time for students to be engaged in professional learning is very precious, and there are many other more important basic courses with respect to the realistic training.

After the basic characteristics of visual communication design specialty have been analyzed, we must establish a basic training way with clear guidance, which can improve the basic courses in traditional sense, reduce the realistic painting training, strengthen the featured basic modeling and basic color of visual communication design, or add some basic trainings which are more closely associated with subsequent specialty. For instance, strengthen course training of the three components, and attach more emphasis on the ability of professional practice according to characteristics of the major orientation, enabling students to gain certain professional knowledge and professional skills from the basic courses.

\section{B. Basic System of Emphasizing Extension and Development}

Many courses of the basic system of conventional visual communication design have their own position, which cannot form systematic curriculum education system. Especially the foundation part is not closely related to the professional part, which often results in students' learning of foundation part is without purpose, and as for the professional part, their independency learning will be influenced due to the weak foundation. Therefore, the establishment of basic system reasonably combined with professional courses, will enhance students' learning efficiency, and the disadvantages brought by single course mode will be avoided.

In course teaching arrangement of this major, the extension and development of the system shall be reflected between basic courses and professional courses, forming an interconnected and complete system. Each course in the professional learning shall be essential and have a clear purpose, playing a role of connecting. The complete and rigorous basic system may enable students to find their own position in the professional study, make clear their own direction, thus to study down-to-earth and step by step.

\section{Develop the Basic System of Combining Theory and Practice}

The feature of visual communication design specialty is to emphasize the practicality, professional learning ability and knowledge must be tested in practice. After the systemic analysis of teaching purpose, we shall pay attention to the combination of basic course, professional course and practice course as for the construction guidance of professional basic system.

In the establishment of basic system, we shall pay attention to the technical courses such as computer aided design, and the cohesion of applied course such material technology, and these courses form the only way to professional practice. The establishment of such correlations can help students better realize the combination of theory and practice in professional learning. In the actual course education, we shall constantly train the students' operation ability, and such training should be reflected in the specific practice items such as hand drawing, software and photography. We shall combine the basic system with social demand and professional development, exercise the students' professional ability, improve the level of students' practice, thus to cultivate excellent applied talents of visual communication design.

\section{INNOVATIVE BASIC EDUCATION SYSTEM OF VISUAL COMMUNICATION DESIGN}

The associated relation with basic course, professional course and practice course as the correlated development shall be formed for construction of innovative basic education system of visual communication design. The innovation of basic education system lies in the "basic", which focuses on the cultivation of students' innovative thinking, pays attention to students' basic learning ability. Students should have certain professional ability in addition to the basic knowledge and theory of visual communication design specialty. This system will help students have a systemic understanding and outlook of the subsequent professional learning, makes students love their specialty more under the innovative transformation of basic education.

According to these innovative ideas, we must construct basic education on the basis of the courses themselves, and modify the traditional courses. Many courses that developed from arts and crafts education are the extension and reflection of traditional Chinese design culture, and the teaching purpose and requirements of the courses shall be modified, to construct the nationalized modern design language. And the unreasonable courses shall be removed and integrated, as some of the old teaching objectives and requirements of these courses are different from the objectives and requirements of modern design education. Strengthen the important courses, perfect the teaching content, increase the teaching hours, pay attention to the subsequent development of the courses and the association and cohesion with other professional courses. Develop new courses, improve the basic system, to adapt to the new design field, and innovate constantly to lead the changes of in the times.

To sum up, the innovative basic education system of visual communication design shall include systematic design modeling, design color, the three components and graphic images, and the basic teaching requirements of combination of theory and practice must run through the course teaching requirements. In this process, the beneficial research and innovation shall also be conducted in many aspects such as teaching mode, teaching method, teaching content, teaching material and teaching plan. Through the exploration and innovation on the basic education system of visual communication design based on the teaching reality of our visual communication design and by referring to western design professional education courses in combination with the actual situation of visual communication design in our country, our visual communication design specialty education cultivate a batch of design talents along with our country's modern development. 


\section{REFERENCES}

[1] Chen Ying. Creative Thinking Training of Art Design [M]. China Textile Press, 2010

[2] Ren Jian. Basic Course of Art Design Specialty [M]. Liaoning Fine Arts Publishing House, 2010

[3] Li Yanzu. Foreign Classic Works Selected Readings in Design Art [M]. Tsinghua University Press, 2006

[4] Li Lixin. Research Method of Artistic Design [M]. Jiangsu Fine Art Press, 2010

[5] Yang Deguang. Introduction to Higher Education [M]. East China Normal University Press, 2010

[6] Qian Chuxi. Art Education Theory and Practice of Contemporary Developed Countries. [M]. East China Normal University Press, 2010 